\title{
DOPPLER ULTRASOUND, AS VITAL AID TO PREDICT FETAL OUTCOME IN HIGHRISK PREGNANCIES
}

\begin{tabular}{ll} 
Dr Lalit D. Kapadia & Associate Professor, OBGYBJMC, Ahmedabad \\
\hline Dr Brinda patel* & 3rd Year Resident, OBGYBJMC, Ahmedabad. *Corresponding Author \\
\hline Dr Amrita Patel & Assitant Professor, OBGYBJMC, Ahmedabad \\
\hline \hline
\end{tabular}

ABSTRACT INTRODUCTION:Pulsed Doppler ultrasound allows a clearer understanding of hemodynamic changes and has thus become one of the most effective clinical methods in

highrisk pregnancies for fetomaternal surveillance.Fetuses with abnormal flow velocity waveform exhibit a high rate of perinatal asphyxia and death compared to those with normal flow properties.Doppler velocimetrydetermines not only the frequency of antenatal testing and the optimum delivery time, but also the mode of delivery.

OBJECTIVE: To evaluate fetal outcome in High Risk Pregnancies with Doppler changes.

MATERIAL AND METHODS: Fetal outcome of 100 high risk pregnancies with doppler changes showing abnormality were analysed over a period of 4 months from May 2020 to August 2020. Ultrasound was done followed by Doppler evaluation. Uterine, umbilical and middle cerebral artery flow velocity waveforms (FVW) were analyzed and the resistance index (RI), pulsatility index (PI) and the systolic/diastolic (S/D) ratios were measured. Fetal outcome was determined by APGAR score after 5minute.

RESULTS:Out of 100 cases, 43 patients underwent vaginal delivery, out of which 25 full term and 18 were preterm deliveries. 57 patients underwent caesarean section out of which 33 were full term and 24 were preterm. Out of 88 live births, 22 babies had APGAR $<6$ at 5 minutes and 34 babies required NICU admission because of fetal distress, low birth weight, low APGAR, respiratory distress syndrome and IUGR.

CONCLUSION: Doppler can be used as promising adjunct in management of high risk pregnancies. It helps in guiding early intervention and improving fetal outcome.

KEYWORDS :Colour Doppler, High Risk Pregnancies, Perinatal outcome

\section{INTRODUCTION}

Pregnancy is considered to be high risk when potential complications can affect mother, baby or both. High risk pregnancy refers to either identification of high risk factors like anemia, cardiac disease, systemic hypertension, thyroid, diabetes mellitus, renal disorder, $\mathrm{Rh}$ alloimmunization, connective tissue disorders during antenatal period in the previous or current pregnancy like Anemia, Gestational hypertension, Pre-eclampsia, Eclampsia and Gestational diabetes mellitus that leads to poor maternal orfetal outcome[1].

The key objective of antenatal fetal surveillance is to detect fetal compromise, assess fetal wellbeing, and enhance perinatal outcomes in normal and highrisk pregnancies in order to take prompt and appropriate action to minimize maternal and perinatal mortality and morbidity rates. Doppler ultrasound allows a clearer understanding of hemodynamic changes and has thus become one of the most effective clinical methods in highrisk pregnancies for fetomaternal surveillance.Fetuses with abnormal flow velocity waveform exhibit a high rate of perinatal asphyxia and death compared to those with normal flow properties. Doppler velocimetry determines not only the frequency of antenatal testing and the optimum delivery time, but also the mode of delivery, whether to carry out conservative management or interventions to reduce maternal and neonatal mortality [2].With the introduction of doppler ultrasound examination it became possible to assess the uteroplacental blood flow, fetoplacental blood flow and fetal blood circulation. Maternal disorders or placental conditions that are known to obliterate small muscular arteries in the placental tertiary stem villi result in a progressive decrease in end diastolic flow in the umbilical artery Doppler Waveform which later becomes absent and then reversed flow during diastole eventually.[3] Reversed end-diastolic flow in the umbilical arterial circulation is an indication of advanced stage of placental compromise and has been associated with obliteration of about $70 \%$ of arteries in placental tertiary villi.[4,5] Absent flow or reversed end-diastolic flow in the umbilical artery are found commonly associated with severe intrauterine growth restriction (IUGR) and oligohydramnios[6,7].

\section{MATERIAL AND METHODS}

The prospective study was conducted in 100 high risk pregnant women with color doppler changes in department of obstetrics and gynecology, civil hospital, Ahmedabad fromMay 2020 to August 2020. Initial assessment consisted of a detailed history of the patient as per the proforma. The study population was selected on the basis of following inclusion and exclusion criteria.

\section{INCLUSION CRITERIA}

- Singleton pregnancy more than 28 weeks of gestation

- Presence of high-risk factors like Gestational Hypertension, Preeclampsia, chronic hypertension, diabetes mellitus overt and GDM, postdated pregnancy, IUGR, Rh negative pregnancy and pregnancy with other medical disorder

\section{EXCLUSION CRITERIA}

- Pregnancy with documented congenital anomaly/ chromosomal anomaly

- Multiple pregnancy

\section{METHOD OF STUDY}

Informed written consent from the antenatal women were obtained after explaining the procedure, its advantages and the absence of any radiation hazards to the fetus or herself in detail. Thorough general and obstetric history was elicited and recorded. General examination, systemic examination and obstetric examination were done. Ultrasound was done followed by Doppler evaluation. Uterine, umbilical and middle cerebral artery flow velocity waveforms (FVW) were analyzed and the resistance index (RI), pulsatility index (PI) and the systolic/diastolic (S/D) ratios were measured. On the 
basis of flow velocity waveforms (FVW), the uteroplacentofetal blood flow was classified as normal, increased resistance to flow, absent end diastolic flow (AEDF) and reversed end diastolic flow (REDF). In case of reversed and absent end diastolic flow decision to terminate pregnancy irrespective of gestational age was taken. Serial Doppler study was done depending on the need.

Decision to deliver was taken in situations such as

- Gestational age-37 weeks for hypertensive mothers

- Absent end diastolic flow

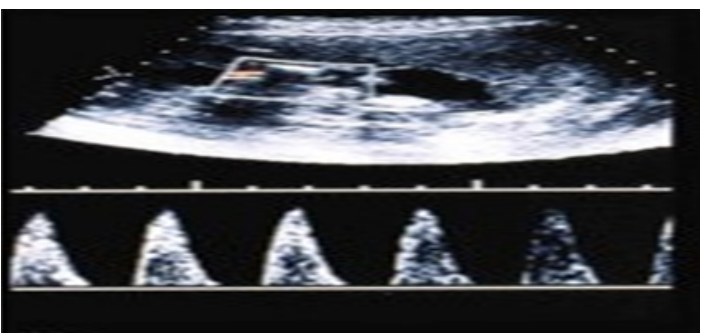

Figure 1: AEDF in umbilical artery

- Reversed end diastolic flow

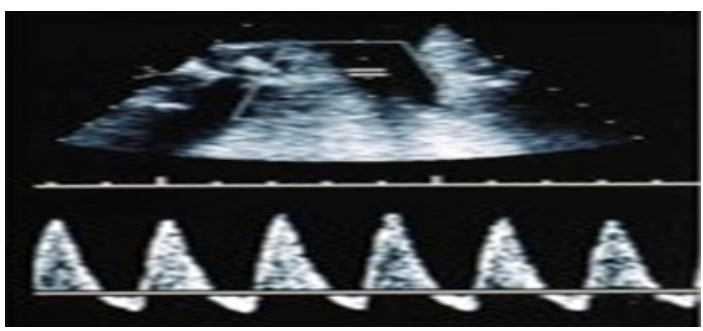

Figure 2: REDF in umbilical artery

- Abruption

- Worsening of maternal conditions like HELLP, Imminent eclampsia, uncontrolled hypertension and deteriorating renal function.

- Evidence of Fetal distress either by Biophysical profile or abnormal cardiotocography (CTG)

- Oligohydramnios

Mode of delivery, gestational age at delivery whether delivery was induced or spontaneous, mode of deliverylabor natural/ elective or emergency LSCS was noted Following were taken as adverse Perinatal outcome

- Preterm delivery

- IUGR

- APGAR at 5 minutes less than $6 / 10$

- Admission to NICU requiring oxygen support/ inotrop support

- Perinatal death and still birth

\section{RESULT}

In the present study, majority women were in age group of 2235 years. 55 patients were primigravida and 45 patients were multigravida.

TABLE 1- Distribution of cases in relation to obstetrics risk factors

\begin{tabular}{|l|l|}
\hline OBSTETRICS RISK FACTORS & NO. OF PATIENTS (n=100) \\
\hline Oligohydramnios & 15 \\
\hline Pre-eclampsia & 35 \\
\hline IUGR & 28 \\
\hline Post-date pregnancy & 6 \\
\hline Cardiac disease & 4 \\
\hline Anemia & 3 \\
\hline $\begin{array}{l}\text { Gestational Diabetes Mallitus } \\
\text { (GDM) }\end{array}$ & 5 \\
\hline Overt Diabetes Mallitus & 3 \\
\hline Rh Isoimmunization & 1 \\
\hline
\end{tabular}

Table 1 shows majority of patients in study are of preeclampsia followed by IUGR, oligohydramnios and postdate pregnancy.

TABLE 2-Finding of Abnormal Doppler in Cases

\begin{tabular}{|c|c|c|c|c|c|c|}
\hline \multirow[t]{2}{*}{\begin{tabular}{|l|} 
Uterine \\
Artery \\
(Increas \\
ed S/D \\
ratio \\
with \\
Diastoli \\
c Notch)
\end{tabular}} & \multicolumn{3}{|c|}{ Umbillical Artery } & \begin{tabular}{|l|} 
Middle \\
Cerebra \\
l Artery \\
i.e. \\
brain \\
sparing \\
effect \\
(decrea \\
se S/D \\
ration \\
and PI)
\end{tabular} & $\begin{array}{l}\text { No. of } \\
\text { Patients } \\
(n=100)\end{array}$ & $\begin{array}{l}\text { percen } \\
\text { tage }\end{array}$ \\
\hline & \begin{tabular}{|l|} 
Decrea \\
se \\
Diastol \\
ic Flow \\
(Increa \\
sed PI \\
and \\
S/D \\
ratio)
\end{tabular} & \begin{tabular}{|l|} 
Absent \\
End \\
Diastoli \\
c Flow \\
(AEDF)
\end{tabular} & \begin{tabular}{|l|} 
Reversa \\
l of End \\
Diastoli \\
c \\
Flow \\
(REDF)
\end{tabular} & & & \\
\hline - & Yes & - & - & 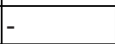 & 32 & $32 \%$ \\
\hline Yes & Yes & - & - & Yes & 13 & $13 \%$ \\
\hline Yes & - & Yes & - & Yes & 21 & $21 \%$ \\
\hline Yes & - & - & Yes & Yes & 14 & $14 \%$ \\
\hline Yes & - & - & - & - & 20 & $20 \%$ \\
\hline
\end{tabular}

Majority of doppler changes associated with preeclampsia Oligohydramnios, IUGR and postdate pregnancies. Among these patients, grave prognosis was seen in patients with reversal of flow in umbilical artery. 14 cases with REDF in umbilical artery and brain sparing effect required Urgent intervention in form of emergency cesarean section out of 12 were preterm cesarean section, 8 babies APGAR $<5$ and required resuscitation, intubated and taken to NICU.

TABLE 3- Distribution of Cases according to Mode of Delivery

\begin{tabular}{|l|l|l|l|}
\hline $\begin{array}{l}\text { Mode of } \\
\text { Delivery }\end{array}$ & Full term & Preterm & $\begin{array}{l}\text { No. of patients in } \\
\text { percentage(n=100) }\end{array}$ \\
\hline $\begin{array}{l}\text { Vaginal } \\
\text { Delivery }\end{array}$ & 25 & 18 & $43 \%$ \\
\hline $\begin{array}{l}\text { Caesarean } \\
\text { Section }\end{array}$ & 33 & 24 & $57 \%$ \\
\hline
\end{tabular}

In present study, patient induced and by considering low threshold for caesarean section for fetal distress 43 patients underwent vaginal delivery, out of which 25 full term and 18 were preterm deliveries. 57 patients underwent caesarean section out of which 33 were full term and 24 were preterm.

\section{TABLE 4-Neonatal Outcome}

\begin{tabular}{|l|l|}
\hline Characteristics & No. of Babies \\
\hline Live birth & 88 \\
\hline Still birth & 12 \\
\hline Birth weight $(>2 \mathrm{~kg})$ & 68 \\
\hline Birth weight $(<2 \mathrm{~kg})$ & 32 \\
\hline APGAR SCORE $(>6)$ at $5 \mathrm{~min}$ & 66 \\
\hline APGAR SCORE $(<6)$ at $5 \mathrm{~min}$ & 22 \\
\hline NICU Admission & 34 \\
\hline
\end{tabular}

Out of 100, 88 were live birth and 12 were still birth babies. 68 babies having birth weight of more than $2 \mathrm{~kg}$ while 32 have less than $2 \mathrm{~kg}$.

APGAR score $>6$ at 5 min was observed in 66 babies while 22 babies show APGAR score $<6$ at 5 min. 32 babies required NICU admission. 
DISCUSSION

The colour flow Doppler imaging has already found its place in studying the pathological vascular flow patterns in intrauterine growth restriction and high-risk pregnancy. Its indices provides important information on the hemodynamics of the vascular area under study[8] . Doppler study of the fetal umbilical and middle cerebral arteries helps us to predict the perinatal outcome and modify the management accordingly. In a present study out of 100 , most commonly found complication with doppler changes was pre-eclampsia followed by IUGR and oligohydramnios. Highly increased resistance flow in umbilical artery seen as AEDF and REDF is a good marker of hypoxic and acidotic fetus which requires termination of pregnancy. Fetuses with absent and reverse end diastolic flow were at a significantly increased risk for delivery at low gestation, IUGR, low birth weight and perinatal deaths. The fetus responds to asphyxia by increasing flow to cerebral hemisphere, i.e. decrease in resistance in MCA is a sign of a compromised fetus and increase flow is a compensatory sign, so called brain sparing effect. A continue insult to the fetus causes decrease in flow as a terminal event so reversal of brain sparing effect in fetus is indicative of grave fetal distress.Abnormal Umbillical artery doppler waveforms associated with IUGR and pre-eclampsia pregnancies. In our study, 14 cases of REDF in umbilical artery with brain sparing effect required emergency cesarean section. In our study, out of 100 cases, 57 cases required cesarean section. Out of 88 live births, 22 babies have APGAR $<6$ at 5 minutes and 34 babies required NICU admission because of fetal distress, low birth weight, low APGAR, respiratory distress syndrome and IUGR.

\section{CONCLUSION}

Doppler can be used as promising adjunct in management of high risk pregnancies. The positive predictive value for assessment of fetal Doppler flow velocimetry has revolutionized the diagnosis of abnormal blood flow the foetoplacental bed, and early identification of these abnormal patterns are useful in the determining the optimal time for delivery to reduce the perinatal mortality. Perinatal mortality increased with abnormality of fetal doppler. It is generally accepted that the findings of AEDF and REDF in umbilical artery is reliable sign of imminent fetal asphyxia and require intervention even in case where Cardiotocography is still normal. Serial doppler study should be done to detect improving or deteriorating trend and timely obstetric intervention in fetal interest.RECOMMENDATION:Doppler should be used as routine investigation as a part of antepartum surveillance in high risk pregnancies.

\section{REFERENCES}

1. 1 High risk pregnancy management options, David James, 4 th edition.

2. MohtKhalide, Shagufta Wahab, Vijay kumar, Saifullah Khalid, Soafia Haroon, Noor A Sabzposh. Doppler indices in prediction of fetal outcome in hypertensive pregnant women NJOG. 2011; 6(1):28-34.

3. Trudinger BJ, Stevens D, Connelly A, et al. Umbilical artery flow velocity waveforms and placental resistance: the effect of embolizations of the umbilical circulation. Am J ObstetGynecol 1987;157 (2):1443-8.

4. Kingdom JC, Burrell SJ, Kaufmann P. Pathology and clinical implications of abnormal umbilical artery Doppler waveforms. Ultrasound ObstetGynecol $1997 ; 9(4): 271-86$.

5. Morrow RJ, Adamson SL, Bull SB, Ritchie JW. Effect of placental embolization on the umbilical artery velocity waveform in fetal sheep. Am J ObstetGynecol 1989;161 (6):1055-60

6. McIntire DD, Bloom SL, Casey BM, Leveno KJ. Birth weight in relation to morbidity and mortality among newborn infants. N Engl J Med 1999;340 (3):1234-8.

7. Copel JA, Reed KL. Doppler ultrasound in obstetrics and gynecology, lst ed. New York, NY: Raven Press; 1995:187-98.

8. Kurjak A, Kupesic S, Zudenigo D. Doppler ultrasound in all three trimesters of pregnancy. CurrOpinObstetGynecol 1994; 6 (5):472-8. 